Research Article

\title{
Safety Aspects of People Exposed to Ultra Wideband Radar Fields
}

\author{
Marta Cavagnaro, Stefano Pisa, and Erika Pittella \\ Department of Information Engineering, Electronics and Telecommunications, Sapienza University of Rome, Rome 00184, Italy
}

Correspondence should be addressed to Marta Cavagnaro; cavagnaro@die.uniromal.it

Received 5 October 2012; Accepted 24 December 2012

Academic Editor: Renato Cicchetti

Copyright (C) 2013 Marta Cavagnaro et al. This is an open access article distributed under the Creative Commons Attribution License, which permits unrestricted use, distribution, and reproduction in any medium, provided the original work is properly cited.

\begin{abstract}
The safety aspects of people exposed to the field emitted by ultra wideband (UWB) radar, operating both in the spatial environment and on ground, for breath activity monitoring are analyzed. The basic restrictions and reference levels reported in the ICNIRP safety guideline are considered, and the compliance of electromagnetic fields radiated by a UWB radar with these limits is evaluated. First, simplified analytical approaches are used; then, both a 3-dimensional multilayered body model and an anatomical model of the head have been used to better evaluate the electromagnetic absorption when a UWB antenna is placed in front of the head. The obtained results show that if the field emitted by the UWB radar is compliant with spatial and/or ground emission masks, then both reference levels and basic restrictions are largely satisfied.
\end{abstract}

\section{Introduction}

Ultra wideband radars have unique features suitable for a large variety of biomedical sensing applications, as for example, the continuous monitoring of breath activity, the monitoring of internal organ movements, the measurement of the heart rate variability, and the pregnancy monitoring.

The first UWB radar for remote sensing was patented in 1994 by McEwan at the Lawrence Livermore National Laboratory (LLNL) [1]. This kind of radar is constituted by a pulse generator, a UWB receiver, a timing circuitry, a signal processor, and UWB antennas. The pulse generator is based on a pulse repetition interval generator with a repetition rate in the range $1-10 \mathrm{MHz}$ followed by a step-like generator producing a fast rise-time edge. Then, one or more impulseshaping networks convert the fast edge in a signal whose time dependence is Gaussian-like or a higher derivative of the Gaussian pulse [2]. Subsequently, the signal is sent to the transmitting UWB antenna and it is radiated toward the target. Once reflected by the target, the impulse is received by the same or a different UWB antenna, detected by a suitable receiving section $[3,4]$, and processed to evaluate the distance between the antenna and the target.
In accordance with the previous description, the UWB radar radiated signal is a pulse train with a repetition rate in the $1-10 \mathrm{MHz}$ range. Due to the particular applications of UWB radar in medicine, crucial points to investigate are the assessment of the UWB radar radiated field and the study of the compliance with safety guidelines. To this end, since the foreseen applications of the UWB radar are both on ground and inside a spatial environment, the maximum value of the radiated field used in this study will be settled considering the emission masks of the Federal Communications Commission (FCC) [5], defined on imaging systems, and of the space environment [6], referring to the electromagnetic compatibility of the electronic apparatuses [7].

The safety issue related to the exposure of humans to the electromagnetic field emitted by the UWB radar can be evaluated following the guidelines issued by ICNIRP (International Commission on Non-Ionizing Radiation Protection) [8] and referenced in the European regulations [9]. ICNIRP guideline was published in 1998 [8] and recently reconfirmed in the frequency range $100 \mathrm{kHz}-300 \mathrm{GHz}[10]$. This guideline defines basic restrictions, which are restraining values directly linked to health effects, and reference levels, which are limits on the electromagnetic field impinging on 
the subject. Moreover, a distinction between workers, that is, people who are exposed to the electromagnetic field due to their work, and the general population is done, with lower limits settled for this last category of people.

In this work, the safety assessment related to the exposure of people to UWB radar fields is tackled in several ways.

An analytical study is performed first to evaluate the compliance of the UWB radar with ICNIRP safety guidelines under the hypothesis that the maximum allowable levels, extrapolated by FCC and spatial emission masks, are used. Then, this analysis is refined simulating a realistic scenario in which a multilayered body model is placed in front of a UWB antenna. Finally, an anatomical model of the head is taken into account in the presence of the same UWB antenna.

The paper is organized as follows: in Section 2, the ICNIRP guideline is introduced. In Section 3, the compliance of the UWB radar with ICNIRP limits is examined, using a model of the radar for the estimation of the radiated field and using a worst case analytical approach to test compliance with basic restrictions. In Section 4, the electromagnetic absorption is evaluated considering a 3-dimensional multilayered body model and an anatomical model of the human head. Eventually, in Section 5, conclusions are drawn.

\section{Limits and Exposure Levels}

According to FCC [5], a UWB radar used for medical purposes should emit an electromagnetic field whose spectrum covers the $3.1-10.6 \mathrm{GHz}$ band. In this frequency band, the main effect that the electromagnetic field can produce inside the human body is the temperature increase, related to the power absorption [8].

Into the safety guidelines, thermal effects of electromagnetic field are associated to the SAR, defined as the power absorbed per unit mass and measured in $W / \mathrm{kg}$ [8]. Accordingly, in the $100 \mathrm{kHz}-10 \mathrm{GHz}$ band, the ICNIRP guideline settles limits (named "basic restrictions") on the SAR considering both the SAR as averaged over the whole body $\left(\mathrm{SAR}_{\mathrm{WB}}\right)$ and the SAR as averaged over $10 \mathrm{~g}$ in the head and trunk $\left(\mathrm{SAR}_{10 \mathrm{~g}}\right)$ and in the limbs $\left(\mathrm{SAR}_{10 \mathrm{gL}}\right)$, as reported in Table 1. These values are averaged over $6 \mathrm{~min}$ [8]. When near field exposures are considered, since the electromagnetic field distribution may be highly inhomogeneous, and there could be a direct coupling between the electromagnetic field source and the exposed humans, the SAR limits must be considered.

For far field exposure, ICNIRP gives reference levels in terms of electromagnetic field values derived from the basic restrictions through dosimetry considerations.

Reference levels are defined as unperturbed field values spatially averaged over the entire body of the exposed individual. The electric field, magnetic field, and power density reference levels for the general population in the frequency range from $2 \mathrm{GHz}$ to $300 \mathrm{GHz}$ are settled to $61 \mathrm{~V} / \mathrm{m}, 0.16 \mathrm{~A} / \mathrm{m}$, and $10 \mathrm{~W} / \mathrm{m}^{2}$, respectively [8].

Moreover, since the field radiated by the UWB radar is constituted by a pulse train, exposure limits have to be considered for short-term effects, with particular reference
TABLE 1: ICNIRP basic restrictions in the $100 \mathrm{kHz}-10 \mathrm{GHz}$ band [7].

\begin{tabular}{lccc}
\hline & $\begin{array}{c}\mathrm{SAR}_{\mathrm{WB}} \\
(\mathrm{W} / \mathrm{kg})\end{array}$ & $\begin{array}{c}\mathrm{SAR}_{10 \mathrm{~g}} \\
(\mathrm{~W} / \mathrm{kg})\end{array}$ & $\begin{array}{c}\mathrm{SAR}_{10 \mathrm{gL}} \\
(\mathrm{W} / \mathrm{kg})\end{array}$ \\
\hline Workers & 0.4 & 10 & 20 \\
General population & 0.08 & 2 & 4 \\
\hline
\end{tabular}

to the microwave hearing effect [8]. These limits are settled in terms of specific energy absorption (SA) and temporal peak of the electric field. According to ICNIRP, "for pulsed exposures in the frequency range 0.3 to $10 \mathrm{GHz}$ and for localized exposure of the head, in order to limit or avoid auditory effects caused by thermoelastic expansion, an additional basic restriction is recommended. This is that the $S A$ [defined as the time integral of SAR] should not exceed $10 \mathrm{~mJ} / \mathrm{kg}$ for workers and $2 \mathrm{~mJ} / \mathrm{kg}$ for the general public, averaged over $10 \mathrm{~g}$ tissue." (note no. 7, Table 4 in [8]). Furthermore, "although little information is available on the relation between biological effects and peak values of pulsed fields, it is suggested that, for frequencies exceeding $10 \mathrm{MHz}, S_{\text {eq }}$ [i.e., the power density] as averaged over the pulse width should not exceed 1,000 times the reference levels or that field strengths should not exceed 32 times the field strength reference levels".

\section{Compliance Evaluations}

Since in the considered application (i.e., remote monitoring of the breath activity) the exposed subject is mainly in the antenna far field region, reference levels must be considered for safety purposes. On the other hand, because the subject under investigation could move during monitoring, it may happen that the subject could find himself close to the antenna thus taking up the reactive field. Consequently, also basic restrictions have been taken into account. Furthermore, for some particular body positions, the UWB signal could impinge on the subject head; therefore, also SA estimation has been considered [11-13].

To compare the radiated field, the SAR, and the SA values produced by the UWB radar with the limits reported in the ICNIRP standard, three safety factors have been defined as follows:

$$
\begin{gathered}
\mathrm{SE}=\left(\frac{E_{\mathrm{REF}}}{E_{\mathrm{COMP}}}\right)^{2}, \quad \mathrm{SS}=\frac{\mathrm{SAR}_{\mathrm{REF}}}{\mathrm{SAR}_{\mathrm{COMP}}}, \\
\mathrm{SW}=\frac{\mathrm{SA}_{\mathrm{REF}}}{\mathrm{SA}_{\mathrm{COMP}}},
\end{gathered}
$$

where $E_{\mathrm{REF}}$ is the electric field reference value reported in the ICNIRP standard, $E_{\text {COMP }}$ is the computed radiated field, $S A R_{R E F}$ and $S A_{R E F}$ are the values of the SAR and SA settled in the ICNIRP guideline, and $\mathrm{SAR}_{\mathrm{COMP}}$ and $\mathrm{SA}_{\mathrm{COMP}}$ are the computed SAR and SA, respectively. According to the definition, the higher the value of the safety factor, the lower the exposure of the subject.

3.1. Reference Levels in relation to FCC Emission Masks. In the FCC regulations, emission masks are based on EIRP 
measured on a specified bandwidth. According to FCC [5], for UWB medical imaging systems, the radiated emissions between $3.1 \mathrm{GHz}$ and $10.6 \mathrm{GHz}$ shall not exceed the EIRP value of $-41.3 \mathrm{dBm}$, when measured using a resolution bandwidth of $1 \mathrm{MHz}$. Correspondingly, the value reported at a given frequency indicates the maximum allowed EIRP within a bandwidth of $1 \mathrm{MHz}$, centered on that frequency.

To evaluate the maximum amplitude of the source signal allowed by FCC emission mask, the UWB radar model presented in [14] has been used. Simulations have been performed by using the half-heart shaped UWB antenna introduced in [15], by considering a source with a repetition rate of $1 \mathrm{MHz}$ and various time behaviors of the signal. In particular, the Gaussian pulse is given by

$$
V_{S}(t)=V_{0} e^{-(1 / 2)\left(\left(t-t_{0}\right) / \sigma\right)^{2}}
$$

with $\sigma=100 \mathrm{ps}$, and it has been considered together with its first 4 derivatives. For each pulse, the maximum amplitude $V_{0}$ that gives rise to an EIRP in compliance with the FCC emission mask has been computed (see legend in Figure 1).

By considering the fourth derivative of the Gaussian pulse, whose maximum amplitude in compliance with FCC is equal to $1 \mathrm{~V}$, the total $\operatorname{EIRP}\left(\mathrm{EIRP}_{\mathrm{TOT}}\right)$ value has been computed by the following formula:

$$
\operatorname{EIRP}_{\text {Tот }}=\frac{1}{1 \mathrm{MHz}} \int_{f_{L}}^{f_{H}} \operatorname{EIRP}(f) d f
$$

finding a value of $1.76 \mu \mathrm{W}$. The electric field intensity value $1 \mathrm{~m}$ far from the antenna can be evaluated by

$$
E_{\mathrm{rms}}^{2}=\frac{\mathrm{EIRP}_{\mathrm{TOT}} 120 \pi}{4 \pi(1.0)^{2}}
$$

and is equal to $0.007 \mathrm{~V} / \mathrm{m}$. This electric field value is well below the $61 \mathrm{~V} / \mathrm{m}$ reference level defined by ICNIRP. In this case, the safety factor is $\mathrm{SE}=7.6 \cdot 10^{7}$.

Eventually, considering the electric field time behavior obtained at a distance of $1 \mathrm{~m}$ from the radar with the same excitation conditions (in particular considering the fourth derivative of the Gaussian pulse with an amplitude of $1 \mathrm{~V}$ ), the computed electric field peak value is equal to $0.57 \mathrm{~V} / \mathrm{m}$. According to ICNIRP, this value should not exceed 32 times the field strength reference level $(61 \mathrm{~V} / \mathrm{m})$ and hence $1952 \mathrm{~V} / \mathrm{m}$. The corresponding safety factor SE is about $1.2 \cdot 10^{7}$.

\subsection{Reference Levels in relation to Space Environment Emis-} sion Masks. Regarding the electromagnetic compatibility masks of the spatial environment [6], the compliance with Columbus and NASA masks for narrowband emission has been verified for the same UWB radar model previously introduced [14]. Simulations have been performed by using the half-heart shaped antenna [15], a source with a repetition rate of $1 \mathrm{MHz}$ having the time behaviors of a Gaussian pulse with $\sigma=100 \mathrm{ps}$ and of its first 4 derivatives. Also in this case, for each pulse, the maximum amplitude, that gives rise to an electric field in compliance with both Columbus and NASA masks, has been computed. The values are reported in Figure 2.

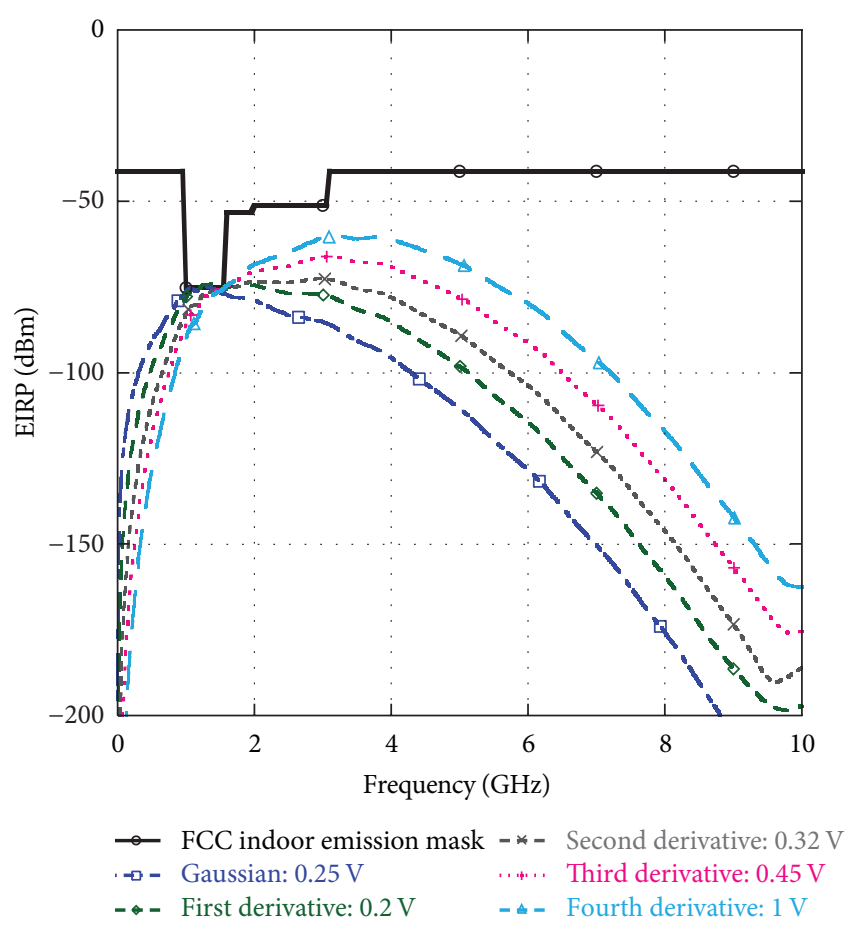

FIGURE 1: Computed EIRP for various pulse shapes achieved with a real UWB antenna. The maximum pulse amplitude that gives rise to EIRP in compliance with FCC indoor emission mask is reported.

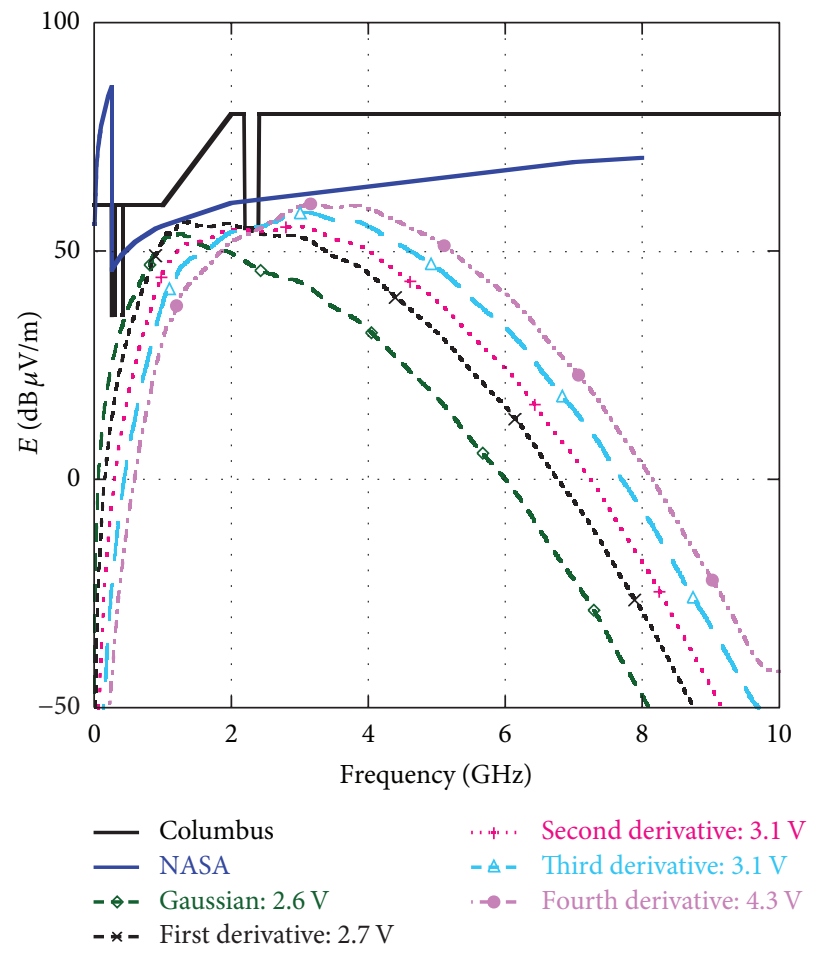

FIGURE 2: Computed $E$-field for various pulse shapes. The maximum pulse amplitude that gives rise to an $E$-field level in compliance with Columbus and NASA emission mask is reported. 
In this case, by considering the fourth derivative of the Gaussian pulse, the maximum EIRP evaluated from (3) is $32.5 \mu \mathrm{W}$. Correspondingly, the maximum electric field intensity value, evaluated from (4), is equal to $0.03 \mathrm{~V} / \mathrm{m}$. The safety factor value is $\mathrm{SE}=4.1 \cdot 10^{6}$. Finally, the electric field time behavior has a peak value equal to $2.48 \mathrm{~V} / \mathrm{m}$ so that the SE is about $0.62 \cdot 10^{6}$.

From the values shown in Figures 1 and 2, it can be noted that the maximum voltage of the pulse generator that gives rise to an electric field that meets the space environment masks is higher than the one that complies with the FCC mask.

3.3. Whole Body SAR. Taking into account the radiated power when the fourth derivative of the Gaussian pulse is applied with its maximum allowable value (see Figures 1 and 2 ), the $S_{A B} R_{W B}$ have been computed, considering a worst case condition in which a man weighting $72.4 \mathrm{~kg}(M)$ absorbs all the radiated power. In this case, the whole body averaged SAR, namely, the power absorbed per unit mass, is

$$
\mathrm{SAR}_{\mathrm{WB}}=\frac{P_{\mathrm{RAD}}}{M}=\frac{1.76 \mu \mathrm{W}}{72.4 \mathrm{~kg}}=2.43 \cdot 10^{-8} \mathrm{~W} / \mathrm{kg} \text {, }
$$

in the case of FCC mask, and

$$
\mathrm{SAR}_{\mathrm{WB}}=\frac{P_{\mathrm{RAD}}}{M}=\frac{32.5 \mu \mathrm{W}}{72.4 \mathrm{~kg}}=4.49 \cdot 10^{-7} \mathrm{~W} / \mathrm{kg} \text {, }
$$

in the case of Columbus and NASA masks.

As it can be noted from (5) and (6), the computed SAR values are well below the $0.08 \mathrm{~W} / \mathrm{kg}$ limit provided by ICNIRP for general population. Regarding the SS safety factor, we obtain

$$
\begin{aligned}
\mathrm{SS} & =\frac{0.08}{2.43 \cdot 10^{-8}}=3.3 \cdot 10^{6} \\
\mathrm{SS} & =\frac{0.08}{4.49 \cdot 10^{-7}}=0.18 \cdot 10^{6}
\end{aligned}
$$

for FCC and spatial masks, respectively.

3.4. SAR Averaged over $10 \mathrm{~g}$. By supposing that the same radiated power is all absorbed in $10 \mathrm{~g}$ mass of the exposed subject, the $\mathrm{SAR}_{10 \mathrm{~g}}$, in the case of FCC mask fulfillment, is given by

$$
\mathrm{SAR}_{10 \mathrm{~g}}=\frac{P_{\mathrm{RAD}}}{M}=\frac{1.76 \mu \mathrm{W}}{0.01 \mathrm{~kg}}=1.76 \cdot 10^{-4} \mathrm{~W} / \mathrm{kg},
$$

while for the spatial masks case, we obtain

$$
\mathrm{SAR}_{10 \mathrm{~g}}=\frac{P_{\mathrm{RAD}}}{M}=\frac{32.5 \mu \mathrm{W}}{0.01 \mathrm{~kg}}=3.25 \cdot 10^{-3} \mathrm{~W} / \mathrm{kg} \text {. }
$$

Also, in this case, the computed SAR value is well below the limit value established by ICNIRP for general population and for the SAR averaged over $10 \mathrm{~g}$ mass, that is, $2 \mathrm{~W} / \mathrm{kg}$. In this case, the SS values are given by

$$
\begin{aligned}
& \mathrm{SS}=\frac{2}{1.76 \cdot 10^{-4}}=1.1 \cdot 10^{4}, \\
& \mathrm{SS}=\frac{2}{3.25 \cdot 10^{-3}}=6.1 \cdot 10^{2},
\end{aligned}
$$

for FCC and spatial masks, respectively.

3.5. SA Evaluations. In order to take into account the possibility that the exposed subject stands with the head in front of the radar antenna, the specific energy absorption has been calculated, starting from the SAR averaged over $10 \mathrm{~g}$ mass. In particular, since the SA is defined as the time integral of SAR over a signal period $T[8]$, it can be obtained as

$$
\mathrm{SA}=\int_{0}^{T} \mathrm{SAR} d t=\mathrm{SAR} \cdot T
$$

For a period $T$ of $1 \mu$ s (equivalent to a pulse repetition frequency of $1 \mathrm{MHz}$ ), we obtain

$$
\mathrm{SA}=1.76 \cdot 10^{-4} \cdot 10^{-6}=1.76 \cdot 10^{-10} \mathrm{~J} / \mathrm{kg},
$$

in the case the radar is used on ground, and:

$$
\mathrm{SA}=3.25 \cdot 10^{-3} \cdot 10^{-6}=3.25 \cdot 10^{-9} \mathrm{~J} / \mathrm{kg}
$$

if the radar operates in the spatial environment.

The computed SA values are well below the limit value established by ICNIRP for the general population that is equal to $2 \mathrm{~mJ} / \mathrm{kg}$. The safety factors (SW) values are

$$
\begin{aligned}
& \mathrm{SW}=\frac{2}{1.76 \cdot 10^{-7}}=1.1 \cdot 10^{7}, \\
& \mathrm{SW}=\frac{2}{3.25 \cdot 10^{-6}}=0.61 \cdot 10^{6}
\end{aligned}
$$

for FCC and spatial masks, respectively.

\section{SA Evaluations in 3D Human Models}

To better evaluate the specific energy absorption, both a multilayered planar model, similar to that studied in [16], and a 3D anatomical model of the head have been considered.

The model used in [16] was derived from the Visible Human (VH) data set [17]. However, other human body models are available for electromagnetic dosimetry studies. In particular, the so-called "Virtual population" comprises a man (Duke, 34-year-old), a woman (Ella, 26-year-old), and several children [18]. While the $\mathrm{VH}$ model represents a relatively big man (1.80 $\mathrm{m}$ tall and $103.0 \mathrm{~kg}$ weight), Duke, being $1.77 \mathrm{~m}$ tall and weighting $72.4 \mathrm{~kg}$, is closer to the "standard man" dimensions.

Starting from the Duke model, a section passing through the head has been considered in order to build a multilayered body model whose tissues and corresponding thicknesses are shown in Table 2. Moreover, the whole Duke's head has been taken into account. 
TABLE 2: Tissues and corresponding thicknesses of a section of the head of the Duke model.

\begin{tabular}{lcc}
\hline & \multicolumn{2}{c}{ Duke model } \\
& Tissue & Thickness $(\mathrm{mm})$ \\
\hline 1 & Skin & 3 \\
2 & Fat & 8 \\
3 & Muscle & 10 \\
4 & Bone & 6 \\
5 & Brain & 50 \\
\hline
\end{tabular}

4.1. SA Evaluations in a 3D Multilayered Model. Specific energy absorption (SA) has been computed by electromagnetic simulations exposing the multilayered model derived from the Duke to the field radiated by the half-heart shaped antenna [15]. The antenna has been excited with a voltage source whose time behavior is the fourth derivative of the Gaussian pulse with amplitude 1V (Figure 3). The electric field as a function of the time has been computed in correspondence with 15 different positions within the layered model, as shown in Figure 3.

Starting from the field values, the SA has been computed according the following relationship:

$$
\mathrm{SA}=\int_{0}^{T} \frac{J(t) E(t)}{\rho} \cdot d t
$$

Figure 4 shows the calculated SA profile in the Duke skin layer (plane $x z$ of Figure 3), while Figure 5 shows the values of the SA computed in the various tissues as a function of the distance from the antenna (direction $y$ of Figure 3). The figures show that the highest value of the SA is found in the skin, right in front of the antenna, and it is equal to $5.9 \mathrm{pJ} / \mathrm{kg}$. By considering a worst case approach in which the $10 \mathrm{~g}$ averaged $\mathrm{SA}$ is supposed to be equal to the peak $\mathrm{SA}$, a value well below the limit of $2 \mathrm{~mJ} / \mathrm{kg}$ established by ICNIRP for the general public is obtained.

4.2. SA Evaluations in the Duke Anatomical Model of the Head. To study a more realistic condition, an electromagnetic analysis has been performed considering the anatomical Duke model of the head exposed to the heart-shaped UWB antenna. In particular, the UWB antenna has been placed $5 \mathrm{~cm}$ far from the head in correspondence with a Duke's eye (see Figure 6).

Figure 7 shows the SA profile computed in the various tissues of the Duke head as a function of the distance from the antenna. As it can be noted from the figure, the highest value of the $\mathrm{SA}$, in correspondence with the eye lens, is equal to $7.9 \cdot 10^{-2} \mathrm{pJ} / \mathrm{kg}$ that is well below the value of $2 \mathrm{~mJ} / \mathrm{kg}$ for the general public established by ICNIRP.

As regarding the computation of the whole body SAR and the SAR as averaged over $10 \mathrm{~g}$ for the Duke's model, the considerations reported in Sections 3.3 and 3.4 can be applied, respectively.

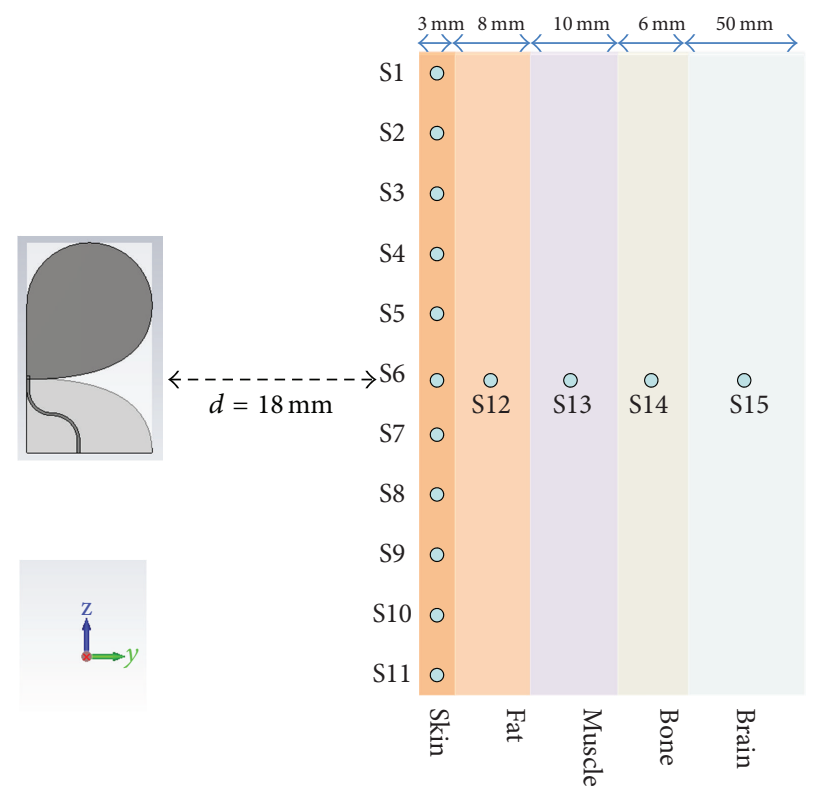

FIGURE 3: UWB antenna in the presence of the multilayered body model.

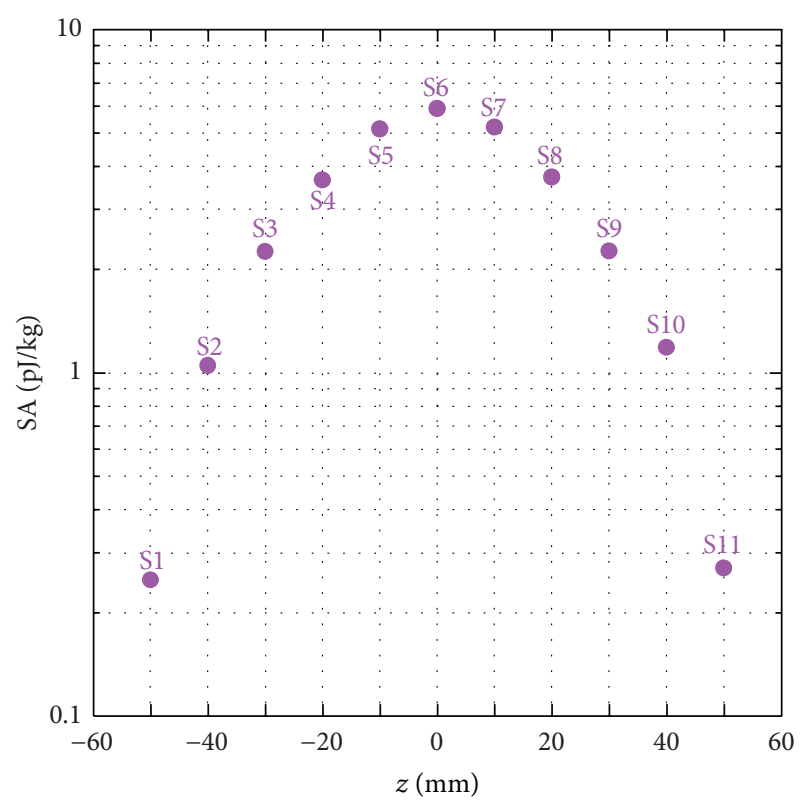

Figure 4: SA evaluated inside the skin tissue.

\section{Conclusions}

This paper addresses the safety aspects of people exposed to the field emitted by ultra wideband radar operating both in the spatial environment and on ground.

The compliance with ICNIRP SAR and SA limits and field exposure levels has been evaluated considering the emission mask issued by the FCC and those to be considered in space environment.

The comparison of the computed electric field values with reference levels issued by ICNIRP reveals that the peak values 


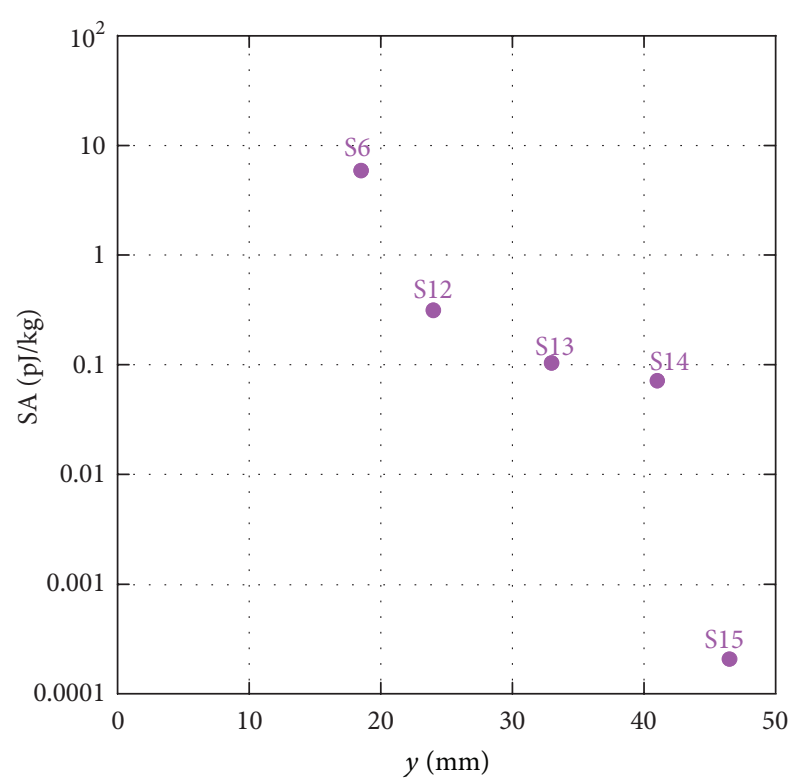

FIGURE 5: SA evaluated inside the various tissues of the considered multilayered body model.

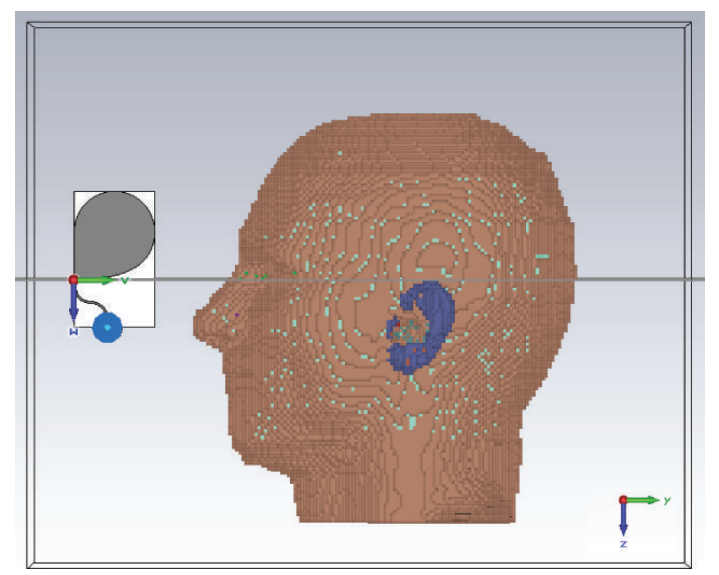

Figure 6: UWB antenna and the anatomical model of the Duke's head.

give rise to lower safety factors with respect to RMS values. Moreover, the safety factor achieved satisfying FCC emission mask is higher than the one evaluated filling the spatial masks.

On the basis of the conducted analysis, the parameter that gives rise to the lower safety factor is the SAR averaged over $10 \mathrm{~g}$ of mass. However, in this case, it has been supposed that all the radiated power is absorbed in $10 \mathrm{~g}$ mass, which is quite an unrealistic hypothesis.

Furthermore, the SA evaluation conducted considering a $3 \mathrm{D}$ electromagnetic model of the Duke placed close a UWB antenna has shown that also, in this case, ICNIRP restrictions are largely satisfied.

In particular, numerical results concerning SA show that simulated values are two-order magnitude lower than the analytical ones evaluated in a worst case condition.

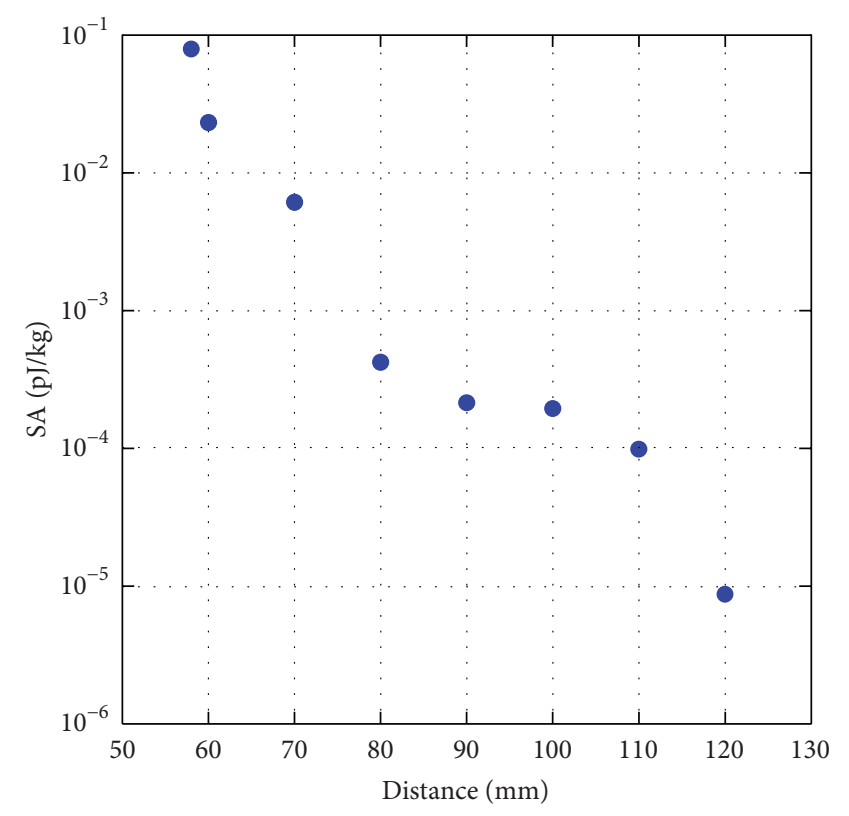

Figure 7: SA evaluated inside the head tissues as a function of the distance from the UWB antenna.

\section{Acknowledgment}

This research is funded by the Italian Space Agency (ASI), under Contract no. I/009/11/0 (NIMURRA Project).

\section{References}

[1] T. E. McEwan, "Ultra-wideband radar motion sensor," US Patent 5,36,070, 1994.

[2] J. R. Andrews, "UWB signal sources, antennas and propagation," Application Note AN-14a, Picosecond Pulse Labs, Boulder, Colo, USA, 2003.

[3] J. D. Taylor and T. E. McEwan, "The micropower impulse radar," in Ultra-Wideband Radar Technology, J. D. Taylor, Ed., pp. 155164, CRC Press, Boca Raton, Fla, USA, 2001.

[4] J. Dederer, B. Schleicher, F. A. T. Santos, A. Trasser, and H. Schumacher, "FCC compliant 3.1-10.6 GHz UWB pulse radar system using correlation detection," in Proceedings of the IEEE MTT-S International Microwave Symposium, (IMS '07), pp. 1471-1474, Honolulu, Hawaii, USA, June 2007.

[5] FCC02-48, "Revision of part 15 of the commission's rules regarding ultra-wideband transmission systems," 2002.

[6] International Space Station, "Space station electromagnetic emission and susceptibility requirements," Revision F, 2001.

[7] P. Russo, V. M. Primiani, A. De Leo, and G. Cerri, "Radiated emission of breath monitoring system based on UWB pulses in spacecraft modules," in Proceedings of the ESA Workshop on Aerospace EMC, pp. 1-6, Venice, Italy, May 2012.

[8] ICNIRP, "Guidelines for limiting exposure to time-varying electric, magnetic, and electromagnetic fields (up to $300 \mathrm{GHz}$ )," Health Physics, vol. 74, no. 4, pp. 494-523, 1998.

[9] Commission of European Communities, Council Recommendation on Limits for Exposure of the General Public to Electromagnetic Fields: $0 \mathrm{~Hz}-300 \mathrm{GHz}$, EC, Brussels, Belgium, 1998. 
[10] ICNIRP, "ICNIRP statement on the 'Guidelines for limiting exposure to time-varying electric, magnetic, and electromagnetic fields (UP to $300 \mathrm{GHz}$ ),' Health Physics, vol. 97, no. 3, pp. 257-258, 2009.

[11] Q. Wang and J. Wang, "SA/SAR analysis for multiple UWB pulse exposure," in Proceedings of the 2008 Asia-Pacific Symposium on Electromagnetic Compatibility and 19th International Zurich Symposium on Electromagnetic Compatibility (APEMC '08), pp. 212-215, Singapore, May 2008.

[12] S. Allen, J. C. Lin, J. B. Anderson et al., "ICNIRP statement on EMF-emitting new technologies," Health Physics, vol. 94, no. 4, pp. 376-392, 2008.

[13] V. De Santis, M. Feliziani, and F. Maradei, "Safety assessment of UWB radio systems for body area network by the $\mathrm{FD}_{2} \mathrm{TD}$ method," IEEE Transactions on Magnetics, vol. 46, no. 8, pp. 3245-3248, 2010.

[14] S. Pisa, P. Bernardi, M. Cavagnaro, E. Pittella, and E. Piuzzi, "A circuit model of an ultra wideband impulse radar system for breath activity monitoring," International Journal of Numerical Modelling, vol. 25, no. 1, pp. 46-63, 2012.

[15] E. Pittella, P. Bernardi, M. Cavagnaro, S. Pisa, and E. Piuzzi, "Design of UWB antennas to monitor cardiac activity," Applied Computational Electromagnetics Society Journal, vol. 26, no. 4, pp. 267-274, 2011.

[16] E. M. Staderini, "UWB radars in medicine," IEEE Aerospace and Electronic Systems Magazine, vol. 17, no. 1, pp. 13-18, 2002.

[17] M. J. Ackerman, "The visible human project," in Proceedings of the IEEE, vol. 86, no. 3, pp. 504-511, March 1998.

[18] A. Christ, W. Kainz, E. G. Hahn et al., "The virtual familydevelopment of surface-based anatomical models of two adults and two children for dosimetric simulations," Physics in Medicine and Biology, vol. 55, no. 2, pp. N23-N38, 2010. 

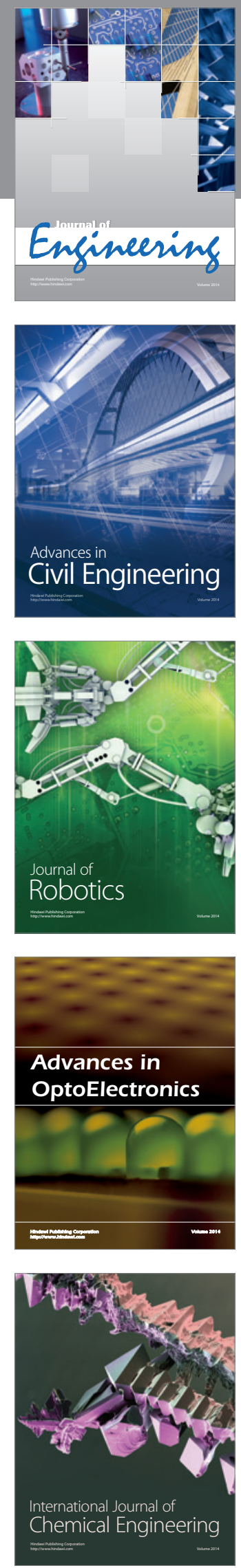

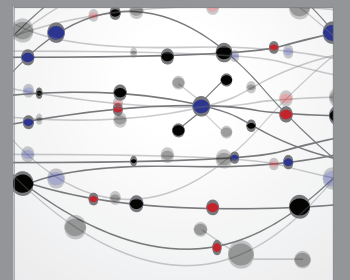

The Scientific World Journal
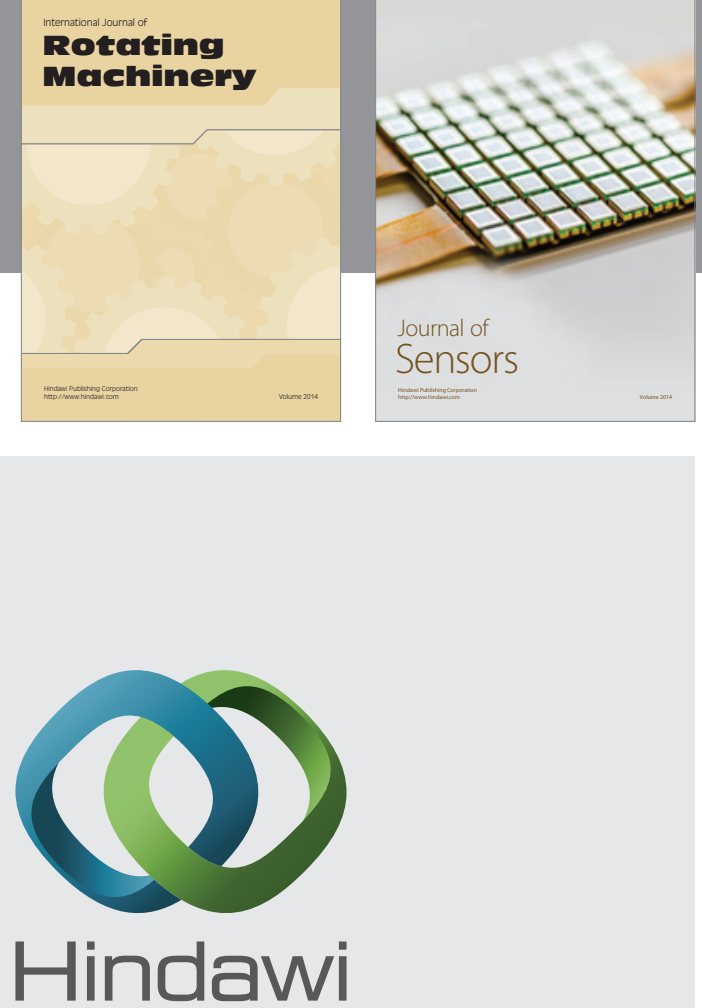

Submit your manuscripts at http://www.hindawi.com
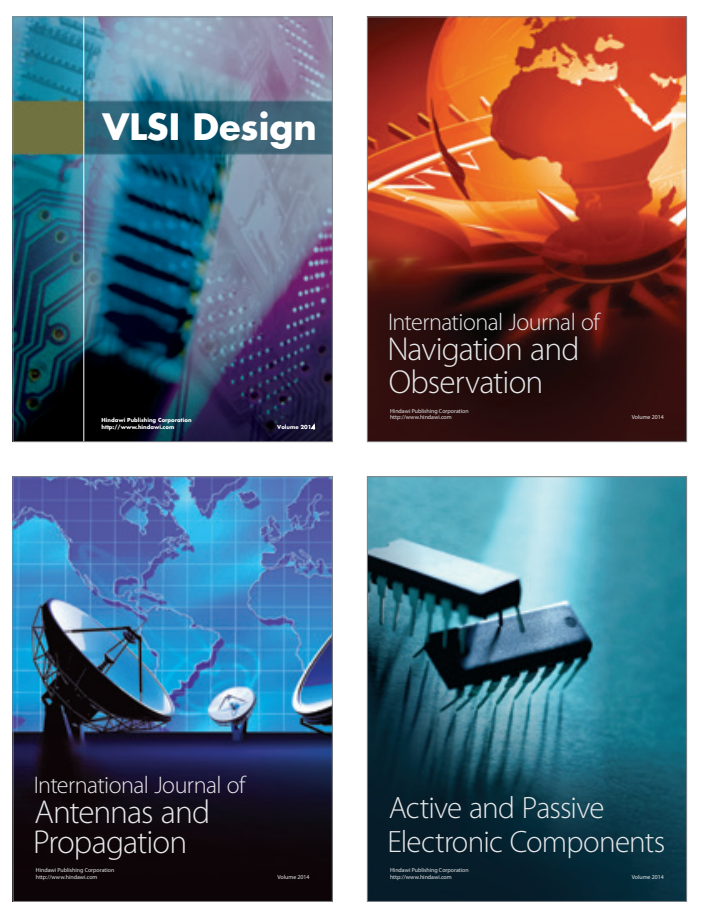
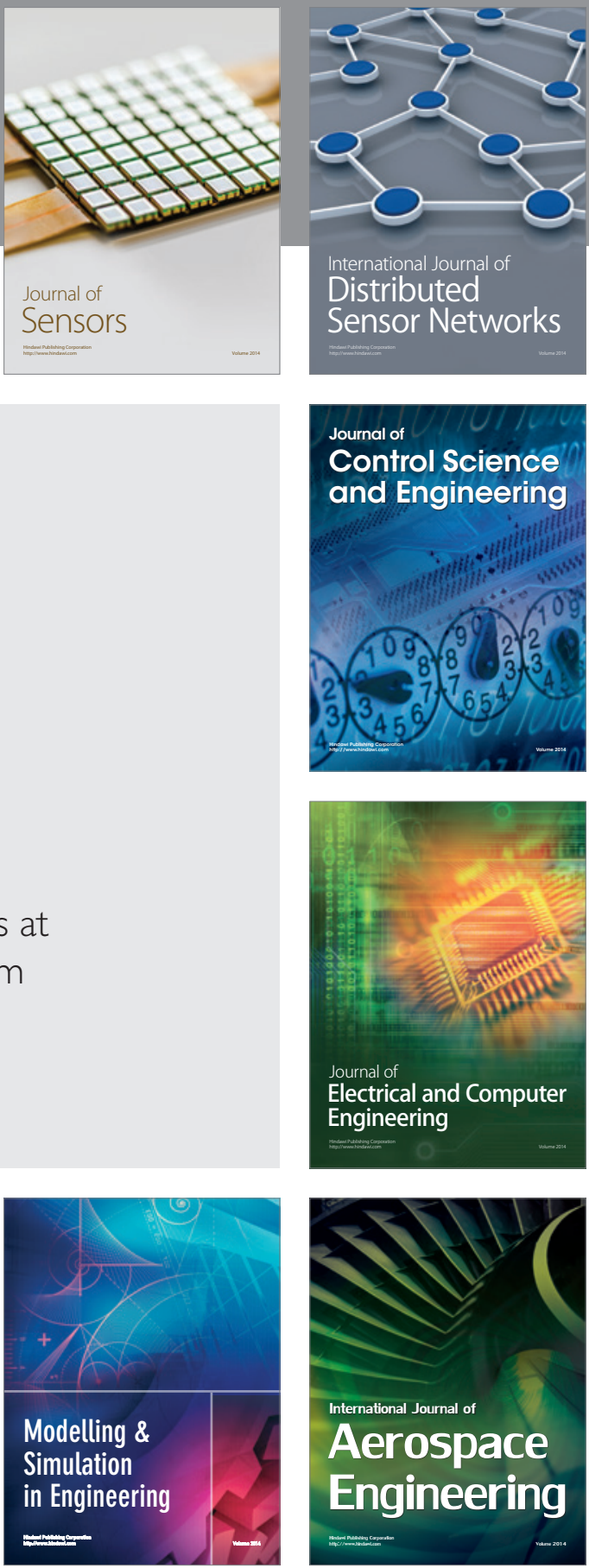

Journal of

Control Science

and Engineering
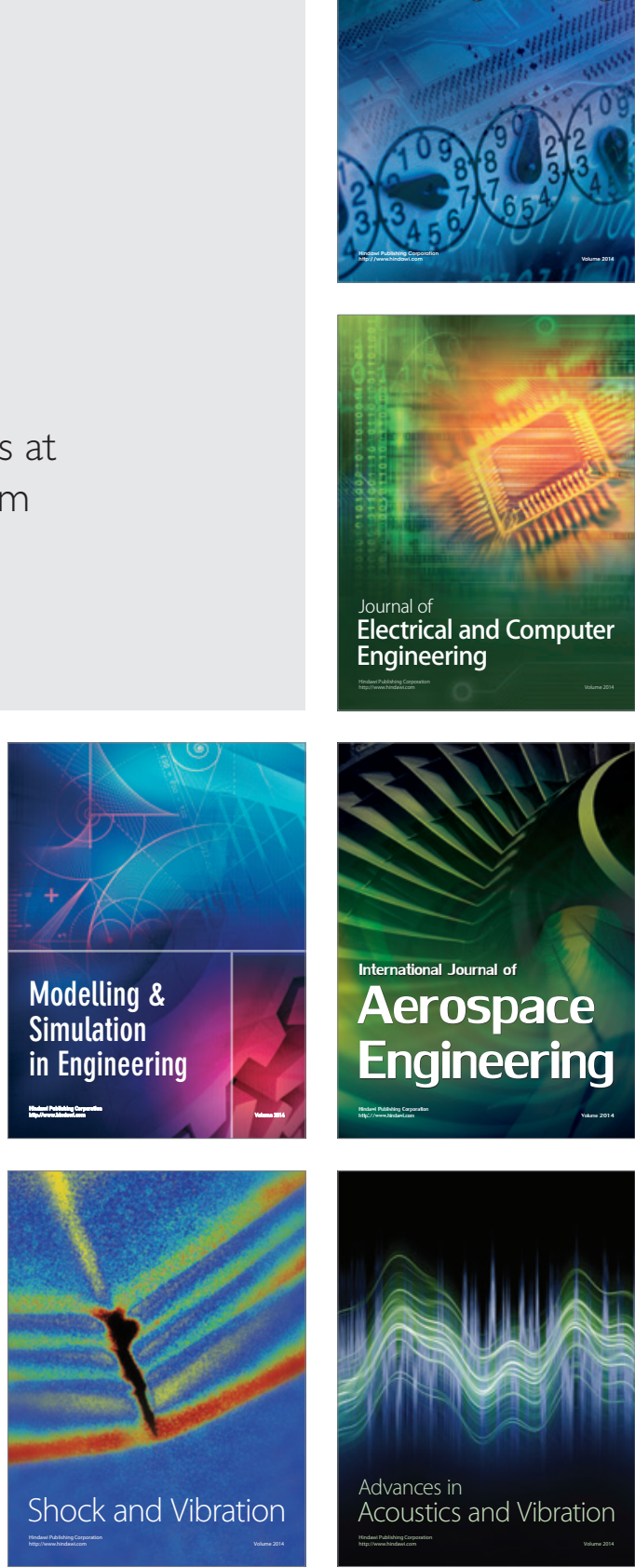